\title{
Visualizing Cold Spots: TRPM8-Expressing Sensory Neurons and Their Projections
}

\author{
Ajay Dhaka, ${ }^{1}$ Taryn J. Earley, ${ }^{1}$ James Watson, ${ }^{2}$ and Ardem Patapoutian ${ }^{1,2}$ \\ ${ }^{1}$ Department of Cell Biology, The Scripps Research Institute, La Jolla, California 92037, and ${ }^{2}$ Genomics Institute of the Novartis Research Foundation, San \\ Diego, California 92121
}

\begin{abstract}
Environmental stimuli such as temperature and pressure are sensed by dorsal root ganglion (DRG) neurons. DRG neurons are heterogeneous, but molecular markers that identify unique functional subpopulations are mainly lacking. ThermoTRPs are members of the transient receptor potential family of ion channels and are gated by shifts in temperature. TRPM8 is activated by cooling, and TRPM8deficient mice have severe deficits in cool thermosensation. The anatomical and functional properties of TRPM8-expressing fibers have not been not comprehensively investigated. We use mice engineered to express the farnesylated enhanced green fluorescent protein (EGFPf) from the TRPM8 locus (TRPM8 ${ }^{E G F P f}$ ) to explore this issue. Virtually all EGFPf-positive cultured DRG neurons from hemizygous mice $\left(T R P M 8^{E G F P f /+}\right)$ responded to cold and menthol. In contrast, EGFPf-positive DRGs from homozygous mice $\left(\right.$ TRPM $8^{\text {EGFPfIEGFPf }}$ had drastically reduced cold responses and no menthol responses. In vivo, EGFPf-positive neurons marked a unique population of DRG neurons, a majority of which do not coexpress nociceptive markers. The fraction of DRG neurons expressing EGFPf was not altered under an inflammatory condition, although an increase in TRPV1-coexpressing neurons was observed. TRPM8 ${ }^{\text {EFFP }}$ neurons project to the superficial layer I of the spinal cord, making distinct contacts when compared with peptidergic projections. At the periphery, TRPM $8^{E G F P f}$ projections mark unique endings in the most superficial layers of epidermis, including bush/cluster endings of the mystacial pads. We show that TRPM8 expression functionally associates with cold sensitivity in cultured DRGs, and provide the first glimpses of the unique anatomical architecture of cold fibers in vivo.
\end{abstract}

Key words: TRPM8; ThermoTRP; DRG; thermosensation; cold; pain

\section{Introduction}

Temperature and pressure is sensed by specialized dorsal root ganglion (DRG) neurons in the trunk, and trigeminal ganglion (TG) neurons in the head (Dhaka et al., 2006; Lumpkin and Caterina, 2007). The cell bodies of DRG neurons are adjacent to the spinal cord within the vertebral column. These neurons send processes to peripheral tissues, detect changes of environmental stimuli within the skin, and relay this information to the spinal cord. DRG neurons are thought to be functionally specialized to sense either noxious or innocuous stimuli, and are divided according to the sensory modalities that they respond to. For example, some respond only to cooling, heating, or pressure, whereas others are polymodal and respond to a variety of thermal and mechanical stimuli. DRG neurons are also characterized by cell size, conduction velocity ( $\mathrm{C}, \mathrm{A} \delta, \mathrm{A} \beta$ fibers, etc.), unique peripheral (epidermis, dermis, Merkel cells, hair follicles, muscle spindle, etc.) targeting, and central projections (dorsal I to ven-

Received Aug. 30, 2007; revised Nov. 13, 2007; accepted Nov. 30, 2007.

This work was supported by National Institutes of Health (NIH) R01 Grants NS046303 and NS049104 and by Novartis Research Foundation. A.D. is the recipient of a Ruth Kirschstein NIH Postdoctoral Fellowship. We thank R. Belvindrah, E. Crotty, M. Garrett, J. Mathur, K. Spencer, and D. Trajkovic for technical assistance and A. Mogrich for invaluable input.

Correspondence should be addressed to Ardem Patapoutian, Department of Cell Biology, ICND202, The Scripps Research Institute, 10550 North Torrey Pines Road, La Jolla, CA 92037. E-mail: apatapou@gnf.org. DOI:10.1523/JNEUROSCI.3976-07.2008

Copyright $\odot 2008$ Society for Neuroscience $\quad 0270-6474 / 08 / 280566-10 \$ 15.00 / 0$ tral X layers of spinal cord) (Julius and Basbaum, 2001; Patapoutian et al., 2003; Lewin and Moshourab, 2004). For example, temperature-sensitive neurons are usually $\mathrm{C}$ and $\mathrm{A} \delta$ (unmyelinated or lightly myelinated) fibers that project to the dorsal horn of the spinal cord. Neurons specifically responding to cooling have been functionally identified using a variety of methods (Hensel and Zotterman, 1951; Hensel et al., 1974; Hensel, 1981; Koltzenburg et al., 1997; Reid et al., 2002). However, a molecular marker that labels such a functionally distinct DRG population had been lacking.

In the past decade, a subset of the transient receptor potential (TRP) family of ion channels was shown to be involved in sensing temperature (Dhaka et al., 2007). The so-called thermoTRPs are activated when expressed in heterologous cells by distinct temperature shifts. For example, TRPM8 is activated by cooling and cooling compounds such as menthol and icilin (McKemy et al., 2002; Peier et al., 2002). Furthermore, TRPM8-deficient mice have dramatically reduced cold-sensitive DRG neurons, and show severe deficits in behavioral cool thermosensation (Bautista et al., 2007; Colburn et al., 2007; Dhaka et al., 2007). These data are in agreement with TRPM8 being the main sensor of innocuous cold. Consistent with this, we had previously shown that TRPM8 is mainly expressed in neurons that do not express nociceptive markers such as heat- and capsaicin-activated TRPV1, CGRP, or IB4 (the latter two mark mainly distinct populations of nociceptive neurons) (Peier et al., 2002). However, tallying 
menthol- and capsaicin-responsive DRG neurons in culture, it was reported that up to 50\% of TRPM8-expressing neurons also express TRPV1, and postulated that these neurons are polymodal nociceptors (McKemy et al., 2002; Babes et al., 2004). The discrepancy between the in vivo expression and the culture results has not yet been resolved, but the increased coexpression has been suggested to reflect an inflammatory or injury state of axotomized cultured neurons (Story et al., 2003). Consistent with some expression of TRPM8 in nociceptive neurons, TRPM8deficient mice have reduced nociceptive-like responses to coldinducing acetone (both acute and in response to injury) (Bautista et al., 2007; Colburn et al., 2007; Dhaka et al., 2007).

Apart from the expression data on TRPM8-positive cell bodies, information on peripheral and central projections of TRPM8 neurons has been almost completely missing. Here we use mice with genetically marked TRPM8 locus to examine in some detail the TRPM8-expressing neurons and their projections. We also show evidence using cultured DRGs that TRPM8-positive neurons are sensitive to cold and menthol, and that this sensitivity is dependent on the presence of TRPM8 protein.

\section{Materials and Methods}

Targeted insertion of EGFPf into the TRPM8 locus. The targeted disruption of the TRPM8 locus and the insertion of EGFPf in frame with the TRPM8 start codon was described previously (Dhaka et al., 2007). EGFPf expression was not visible until after we excised the lox-P-flanked neomycin selection cassette by mating F1 TRPM8-deficient mice to the germline Cre-recombinase EIIA-Cre deleter strain (The Jackson Laboratory, Bar Harbor, ME) on a C57BL/6 background. Progeny positive for Cre-recombinase and the loss of the neomycin selection cassette as verified by PCR were mated to C57BL/6 mice. The resultant hemizygous offspring that were positive for the loss of the neomycin selection cassette and did not express Cre-recombinase were intercrossed to generate N3(F2) littermates used in all studies. PCR verifying the loss of the neomycin cassette was performed using the following primers: EGPF1255, 5'-AAGCGCGATCACATGGTCCTGCTGGAG-3' and Sal13'TM8_R, 5'-AAAAGTCGACTCGCAAAACAA-3', which flanked the selection cassette.

All experiments were conducted with the approval of The Scripps Research Institute Animal Research Committee.

Complete Freund's Adjuvant injections. Intraplantar injections of complete Freund's Adjuvant (CFA) were performed as described previously (Colburn et al., 2007). Briefly, $50 \mu$ l of CFA (suspended in a 1:1 emulsion of saline and heat-killed Mycobacterium tuberculosis in mineral oil) was injected intraplantarly into the left hindpaw of two TRPM $8^{E G P P f /+}$ mice. Mice were killed $48 \mathrm{~h}$ after injection, and the left L4-L6 DRGs were isolated and stained as described below. The neurons that were positive for EGFPf and TRPV1 and the total number of neurons were tallied for each mouse. The results were combined because the percentages of neurons in each category were virtually identical compared against pooled left and right L4-L6 DRG from an uninjected TRPM8 $8^{E G F P f /+}$ mouse.

Calcium imaging. Dissociation and culturing of mouse dorsal root ganglion neurons were performed as described with the following modifications (Story et al., 2003). Dissected DRGs were dissociated by incubation for $1 \mathrm{~h}$ at $37^{\circ} \mathrm{C}$ in a solution of culture medium (Ham's F12/ DMEM with $10 \%$ horse serum, $1 \%$ penicillin-streptomycin) containing $0.125 \%$ collagenase (Worthington Biochemicals, Lakewood, NJ) followed by a $30 \mathrm{~min}$ incubation in $10 \mathrm{ml}$ of culture media plus $1.25 \mathrm{U}$ papain. Calcium imaging was performed essentially as described (Story et al., 2003). Growth media was supplemented with $100 \mathrm{ng} / \mathrm{ml}$ nerve growth factor (NGF) and $50 \mathrm{ng} / \mathrm{ml}$ glial-derived nerve growth factor (GDNF). Experiments were performed $24 \mathrm{~h}$ after plating, and the threshold for activation was defined at $30 \%$ above baseline for cold and menthol and $50 \%$ above baseline for capsaicin.

Immunofluorescence. Adult mice, ages 6-16 weeks, were asphyxiated with $\mathrm{CO}_{2}$ and perfused transcardially with $200 \mathrm{ml}$ of $30 \%$ sucrose in $0.1 \mathrm{M}$ phosphate buffer (PB; pH 7.3) followed by $200 \mathrm{ml}$ of fixative (4\% para- formaldehyde in $0.1 \mathrm{~m} \mathrm{~PB}$, pH 7.3, or Zamboni's fixative [2\% paraformaldehyde, $15 \%(\mathrm{v} / \mathrm{v})$ saturated picric acid, $0.1 \mathrm{~m} \mathrm{~PB}, \mathrm{pH} 7.3])$. The spinal column, TGs, tongue, and mystacial pads were removed and postfixed overnight $(\mathrm{o} / \mathrm{n})$ at $4^{\circ} \mathrm{C}$ in the same fixative. The lumbar spinal cord and DRGs were then carefully dissected. All tissues were cryoprotected $\mathrm{o} / \mathrm{n}$ in $30 \%$ sucrose in $0.1 \mathrm{M} \mathrm{PB}, \mathrm{pH} 7.3$, frozen in optimal cutting temperature medium (OCT), sectioned with a cryostat at $20 \mu \mathrm{m}$, mounted on Superfrost Plus slide, and stored at $-80^{\circ} \mathrm{C}$.

Dissection of glabrous skin was described previously (Zylka et al., 2005). Briefly, glabrous skin was dissected from the hindpaws of nonperfused mice, postfixed o/n in Zamboni's fixative, cryoprotected, and frozen in OCT. Glabrous skin was sectioned at $30 \mu \mathrm{m}$ as free-floating sections, immediately stained, and then mounted on Superfrost Plus slides.

Frozen slides were dried at room temperature for $1 \mathrm{~h}$. Free-floating and slide-mounted sections were washed three times in PBS with $0.1 \%$ Triton X-100 (PBS+ TX), blocked for $30 \mathrm{~min}$ to $1 \mathrm{~h}$ in PBS+ TX containing $10 \%$ goat serum or $10 \%$ donkey serum or $5 \%$ goat serum $+5 \%$ donkey serum, depending on secondary antibodies used, and incubated $\mathrm{o} / \mathrm{n}$ at $4^{\circ} \mathrm{C}$ with primary antibodies diluted in blocking solution. The following antibodies were used: 1:200 rabbit anti-GFP (Invitrogen, Carlsbad, CA), 1:200 chicken anti-GFP (AbCam, Cambridge, MA), 1:800 guinea pig anti-CGRP (Peninsula, Belmont, CA), 1:1000 anti-rabbit NF150 (Millipore, Billerica, MA), 1:1000 guinea pig anti-substance $\mathrm{P}$ (AbCam), 1:1000 anti-rabbit TRPV1 (AbCam), 1:5000 anti-rabbit NK1 (Sigma, St. Louis, MO), 1:100 anti-rabbit NK1 (Advanced Targeting Systems, San Diego, CA), 1:3000 anti-rabbit PGP 9.5 (AbCam), 1:3000 mouse anti-GAD65 (GAD6; Developmental Studies Hybridoma Bank, University of Iowa, Iowa City, IA), 1:1000 mouse anti-GAD67 (Developmental Studies Hybridoma Bank, University of Iowa), 1:1000 rabbit antigustducin (Santa Cruz Biotechnology, Santa Cruz, CA). The sections were then washed three times in PBS+TX and incubated for $2 \mathrm{~h}$ at room temperature with secondary antibodies conjugated to Alexa-568 fluorochrome (Invitrogen) or to FITC, Cy3 fluorochromes (Jackson ImmunoResearch, West Grove, PA), and diluted 1:200 in blocking solution. To detect IB4 staining, Griffonia simplicifolia isolectin, GS-IB4-Alexa 568 (Sigma) diluted 1:100 was incubated during secondary antibody incubation. Sections were then washed three times in PBS+ TX and mounted in anti-fade medium (Vectashield, Vector Laboratories, Burlingame, CA).

Image acquisition. Fluorescence images were collected using an Olympus (Tokyo, Japan) Fluoview 500 confocal microscope by sequential illumination using the 488 line of an argon laser and the HeNe green 543 laser. Merge stacked images of $20-30 \mu \mathrm{m}$ made up of $0.6-1 \mu \mathrm{m}$ optical sections were created using a $20 \times 0.8$ numerical aperture (NA) Plan APO oil-immersion objective or a $60 \times 1.4 \mathrm{NA}$ APO oil-immersion objective (0.34 $\mu \mathrm{m}$ optical sections). Images taken with the $60 \times$ objective were digitally magnified $2 \times$ during imaging.

\section{Results}

\section{Targeting the axonal tracer EGFPf to the TRPM8 locus}

We previously reported the generation of TRPM8-deficient mice by deleting amino acid residues 2-29 and knocking-in the axonal tracer EGFPf followed by an SV40 polyA tail in frame with the start codon (Dhaka et al., 2007). Because EGFPf was not expressed in these mice, we reasoned that the loxP-flanked EM7PGK-Neomycin cassette might be acting to disrupt transcription of the EGFPf gene from the TRPM8 promoter. By mating $T R P M 8^{E G F P f /+}$ mice to the EIIA-Cre germline Cre-recombinase deleter strain, we were able to excise the neomycin cassette, and remarkably observed robust expression of EGFPf.

\section{EGFPf specifically labels menthol- and cold-responsive neurons in culture}

DRG neurons from TRPM8-deficient mice have severe deficits in cold and menthol responses in culture. We used the TRPM $8^{\text {EGFPf }}$ mice to specifically investigate the cold/menthol responses of putative TRPM8-expressing neurons (in the presence and absence of functional TRPM8) with single-cell resolution. We compared 


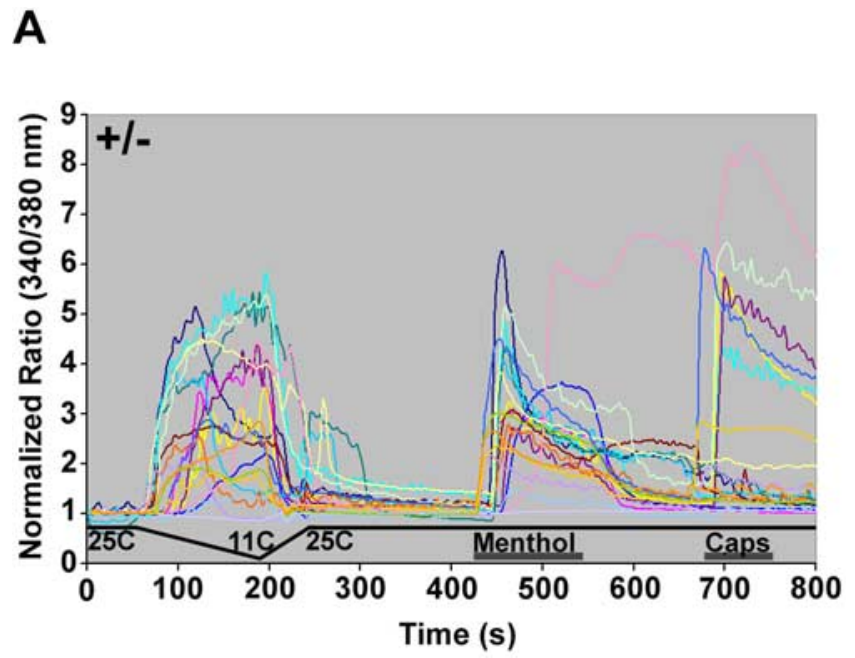

B

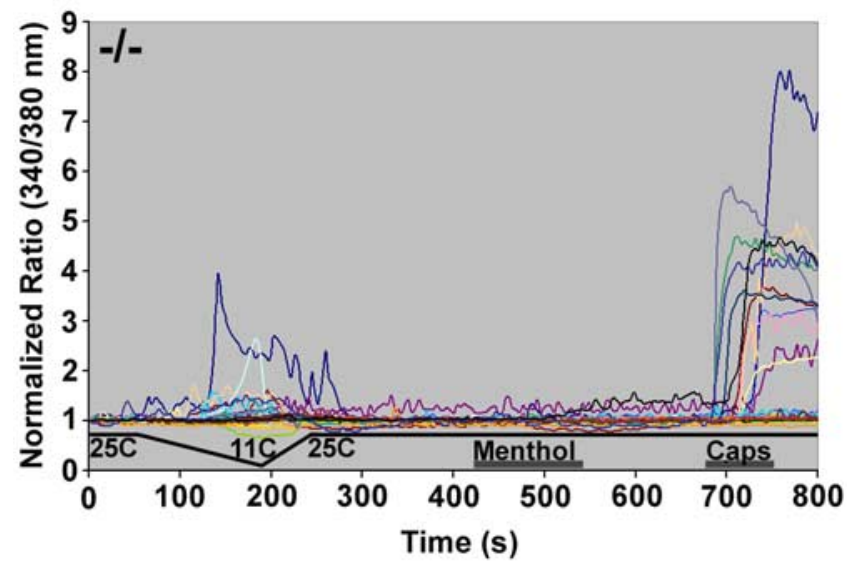

Figure 1. EGFPf neurons from TRPM $8{ }^{\text {EGFPf/+ }}$ mice are activated by cold and menthol. Dorsal root ganglion cells from TRPM $8^{\text {EGPF/+ }}(\boldsymbol{A})$ and TRPM $8^{\text {EGFPf/EGFPf }}(\boldsymbol{B})$ mice were challenged with cold, followed by menthol ( $250 \mu \mathrm{m})$ and then capsaicin (Caps; $1 \mu \mathrm{M})$. Individual traces from all EGFPf-positive neurons are presented.

cold, menthol, and capsaicin (TRPV1 agonist used as control) responses from EGFPf-positive neurons from TRPM8 ${ }^{E G F P f /+}$ and TRPM $8^{\text {EGFPf/EGFPf }}$ mice. When challenged with a cooling ramp $\left(25^{\circ} \mathrm{C}\right.$ to $11^{\circ} \mathrm{C}$ over $\left.120 \mathrm{~s}\right), 19 / 20$ or $95 \%$ of EGFPf-positive neurons from TRPM8 ${ }^{E G F P f /+}$ responded. In contrast, $7 / 32$ or $22 \%$ EGFPf-positive DRG neurons from TRPM8 ${ }^{\text {EGFP/EGFPf }}$ mice showed cooling-induced significant increases in intracellular calcium $\left(\left[\mathrm{Ca}^{2+}\right]_{\mathrm{i}}\right)$. Furthermore, the threshold for cold activation of neurons from mice hemizygous for TRPM8 was $22.4 \pm 0.5^{\circ} \mathrm{C}$ versus $17.2 \pm 1.3^{\circ} \mathrm{C}$ for neurons from homozygous mice (Fig. 1) $(p<0.001)$. These temperatures correlate nicely with the reported thermal thresholds for TRPM8 and noxious cold receptors, respectively, and suggest that at least in cultured neurons a subpopulation of TRPM8-expressing neurons may express additional cold receptors (McKemy et al., 2002, Peier et al., 2002, Story et al., 2003). The fold activation to cold stimulation over baseline was also significantly greater between EGFPf-positive neurons from TRPM $8^{E G F P f /+}$ and TRPM $8^{\text {EGFPf/EGFPf }}$ mice $(3.8 \pm$ 0.4 vs $2.0 \pm 0.3 ; p<0.05$ ) (Fig. 1 ). Importantly, the same $19 / 20$ neurons that responded to cold from hemizygous mice also responded to menthol $(250 \mu \mathrm{M})$, strongly suggesting that EGFPf is marking TRPM8-specific neurons (Fig. 1A). The one green hemizygous neuron that did not respond to cold or menthol also did not respond to capsaicin and may have been sick or wrongly identified (Fig. 1A). None of the EGFPf-positive neurons from TRPM $8^{\text {EGFP/EGFPf }}$ mice responded to menthol, reaffirming that the observed cold responses in GFP-positive neurons in these mice are not caused by TRPM 8 activity (Fig. $1 B$ ). These data support the conclusions that TRPM $8^{\text {EGFPf/EGFPf }}$ mice are null for TRPM8, and that EGFPf is specifically labeling TRPM8expressing neurons (Nealen et al., 2003; Dhaka et al., 2007). Approximately $40 \%$ of both hemizygous and homozygous EGFPf neurons responded to capsaicin, indicating that under these culture conditions, TRPV1 is expressed in TRPM $8{ }^{+}$neurons $(8 / 20$ and 12/32, respectively) (Dhaka et al., 2006).

\section{TRPM8 is expressed in nonpeptidergic and IB4-negative small-diameter neurons}

To characterize the expression of EGFPf in vivo, we analyzed sections of adult DRG, lumbar spinal cord, and skin from TRPM $8^{\text {EGFPf/+ }}$ and TRPM $8^{\text {EGFPf/EGFPf }}$ mice either unstained or stained with antibodies against GFP. In the DRG and spinal cord, endogenous EGFPf fluorescence was robust, and staining with an anti-GFP antibody was not necessary. We observed $100 \%$ overlap between endogenous EGFPf signal and staining with anti-GFP antibody (Figs. $2 A-C, 4 A-C$ ); however, in the periphery, staining with anti-GFP was necessary to fully visualize axonal terminals. In addition, we observed no differences in EGFPf expression (except a detectable increase in endogenous fluorescent intensity in homozygous null mice) and projection patterns between TRPM $8^{E G F P f+}$ and TRPM $8^{\text {EGFPf/EGFPf }}$ mice, suggesting that the survival and the gross patterning of these thermosensitive neurons is not dependent on TRPM8 expression (data not shown). We therefore used both genotypes as indicated in the following experiments.

There are at least three classes of unmyelinated sensory neurons, which can be differentiated based on their growth factor dependence (Snider and McMahon, 1998; Julius and Basbaum, 2001): thermosensitive and peptidergic nociceptive neurons, which are dependent on NGF/TrkA signaling for survival, and nonpeptidergic nociceptive neurons, which are dependent on GDNF/c-Ret signaling for survival and which can be marked by the plant lectin IB4. Using in situ hybridization studies, we have previously shown that TRPM8 is expressed in nonpeptidergic presumptive unmyelinated small-diameter neurons that do not express the nociceptive markers, CGRP, IB4, and TRPV1, representing $5-10 \%$ of total DRG neurons (Peier et al., 2002). Other studies, however, have reported colocalization of TRPM8 and TRPV1 in a small subset of TRPM8-expressing neurons in vivo (Okazawa et al., 2004; Abe et al., 2005). To determine whether EGFPf expression was consistent with these findings, we stained DRG and TG from TRPM $8^{\text {EGFPf/EGFPf }}$ mice with antibodies against a number of neuronal markers (Fig. 2) (data not shown). EGFPf was expressed in small-diameter neurons, colocalized with the pan-neuronal marker PGP 9.5 but not with NF150, a marker for myelinated neurons, and was expressed in 7.8\% (172/ 2207) of DRG neurons and $10.3 \%$ (476/4604) of TG neurons (Fig. $2 D-I$ ) (see below). We also observed no colocalization with IB4 and CGRP (Fig. $2 \mathrm{~J}-\mathrm{O}$ ). We did, however, detect some colocalization with TRPV1 in a subset of EGFPf-positive neurons, probably because of the increased sensitivity of EGFPf compared with our previously used in situ hybridization probe (Figs. $2 P-R$, 3) (Peier et al., 2002). In the TG of TRPM $8^{\text {EGFPf/EGFPf }}$ mice, $10.3 \%$ $(476 / 4604)$ and $18.8 \%(866 / 4604)$ of the neurons expressed EGFPf and TRPV1, respectively, and 18.7\% (89/476) of EGFPf neurons coexpressed TRPV1. 


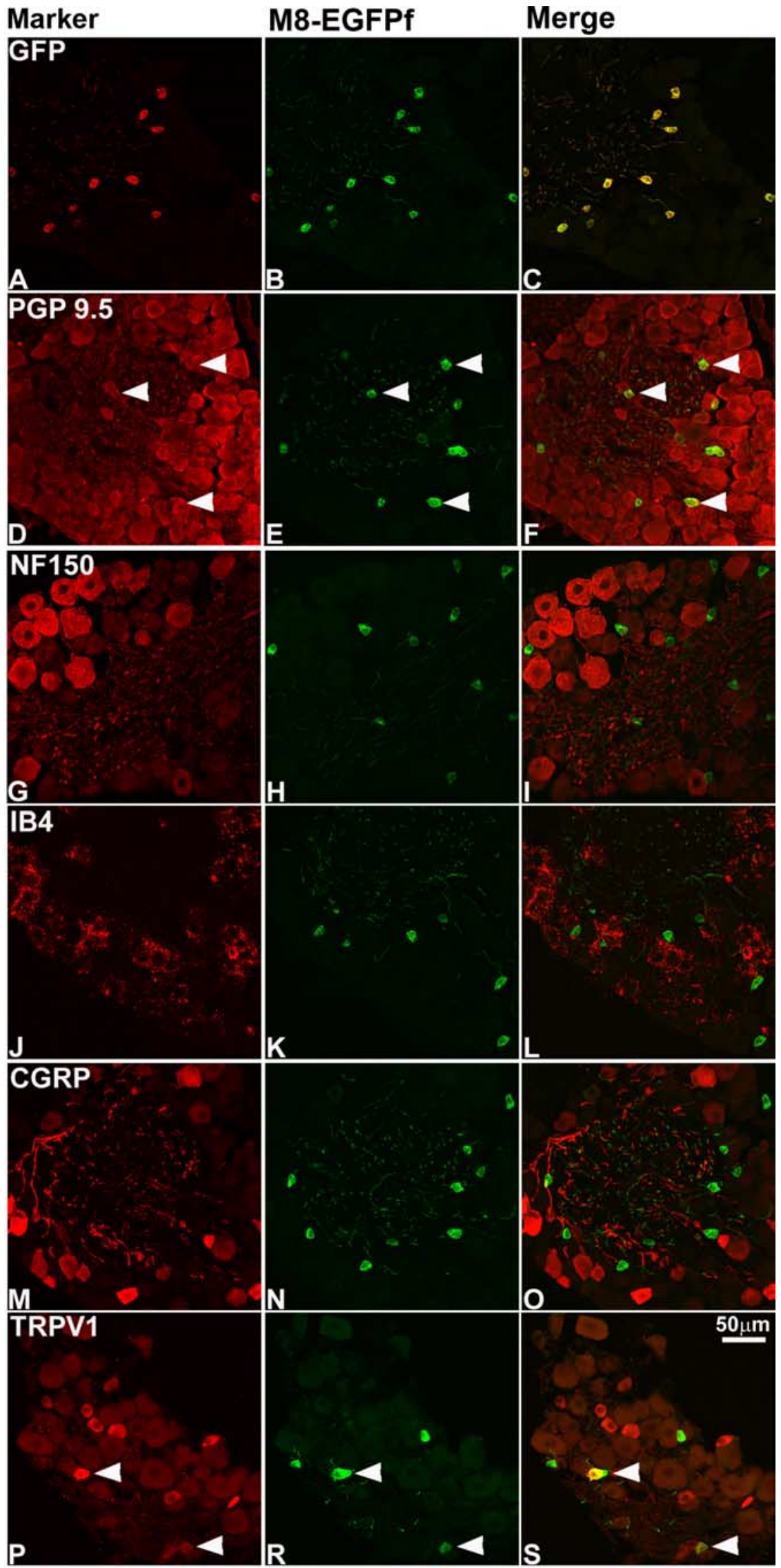

Figure 2. TRPM8 $8^{\text {EGFP }}$ marks a unique population of DRG cell bodies. $A-S$, DRG neurons from TRPM $8^{\text {EGPFf/EGFP }}$ mice were stained with antibodies against GFP and sensory neuron markers (red). TRPM8 ${ }^{\text {EGFP }}$ neurons were visualized by endogenous EGFPf (green). Arrowheads indicate examples of double-labeled neurons. Scale bar (in S) is the same for all panels.
Inflammation does not increase the percentage of TRPM8-expressing neurons but does increase the percentage of TRPM8 neurons expressing TRPV1

We and others using TRPM8-deficient mice have reported that TRPM8 may be involved in acute cold nociception as assayed by acetone-induced nociceptive-like responses (Bautista et al., 2007; Colburn et al., 2007; Dhaka et al., 2007). It has also been shown that both nerve injury and CFA-induced inflammation can cause TRPM8-dependent sensitization to acetone application (Colburn et al., 2007). This together with our data described in Figure 1 and multiple reports of TRPM8 and TRPV1 coexpression in in vivo and in ex vivo sensory neuron cultures (for review, see Dhaka et al., 2006), suggest that TRPM8/TRPV1-expressing neurons may mark a subclass of TRPM8 neurons that code for cold nociception. To test whether acetone sensitivity of TRPM8 after inflammation/injury could be attributable to TRPM8 upregulation (as observed for TRPV1), we asked whether CFA could induce changes in the number of neurons that express TRPM8 (Amaya et al., 2003; Obata et al., 2005). We injected the left hindpaw of TRPM $8^{\text {EGFPf/+ }}$ mice with CFA and collected the left L4-L6 DRGs $2 \mathrm{~d}$ after injection and compared the percentage of EGFPf (TRPM8), TRPV1, and coexpressing neurons to uninjected control L4-L6 DRGs (Fig. 3). One hundred seventytwo of 2207 (7.8\%) and 479/2207 (21.7\%) of control DRGs expressed EGFPf and TRPV1, respectively. Of the EGFPf-positive, $12.2 \%$ (21/172) also expressed TRPV1. In CFAinjected animals, $6.57 \%(334 / 5080)$ and $34.67 \%(1761 / 5080)$ expressed EGFPf and TRPV1, respectively. Of the EGFPf-positive neurons, $18.75 \%$ (63/336) expressed TRPV1. It appears then that although the number of TRPM8-expressing neurons does not change after CFA treatment, the number of TRPV1expressing neurons does increase (as shown before), and TRPV1 expression is present in increasing numbers of TRPM8 neurons (Amaya et al., 2003; Obata et al., 2005).

TRPM8 ${ }^{E G F P f /+}$ neurons project primarily to lamina I of the spinal cord dorsal horn It has been long recognized that the lamina I and the various sublayers of lamina II (which together comprise the dorsal horn) of the spinal cord receive input from $\mathrm{A} \delta$ and $\mathrm{C}$ primary afferent thermoreceptors and nociceptors (Light et al., 1979; Craig and Dostrovsky, 2001). Indeed neurons in lamina I of cats that respond exclusively to innocuous cooling have been identified electrophysiologically (Han et al., 1998). Although TRPM8 antibodies have shown that TRPM $8^{+}$neurons project to the dorsal horn, no detailed infor- 
mation exists (Proudfoot et al., 2006; Bautista et al., 2007). Do TRPM8 projections innervate lamina I or II? Within each lamina, are the projections overlapping or distinct with other known fibers such as CGRP or IB4? We examined the laminar termination of TRPM $8^{\text {EGFPf }}$ neurons by staining spinal cord sections of TRPM8 ${ }^{\text {EGFPf/EGFPf }}$ mice with known markers for specific lamina in the dorsal horn. Nonpeptidergic afferents labeled by IB4 terminate in the inner or middle layer of lamina II (Silverman and Kruger, 1990; Zylka et al., 2005). We observed almost no overlap between TRPM $8^{\text {EGPP }}$ afferents and $\mathrm{IB}^{+}{ }^{+}$afferents (Fig. 4D-F). Peptidergic sensory neurons labeled by CGRP and substance $\mathrm{P}$ project mainly to lamina I and the outer layer of lamina II (McNeill et al., 1988; Todd, 2002). TRPM8 ${ }^{E G F P f}$ afferents primarily terminated in the superficial layer of lamina I and only partially overlapped with CGRP and substance P. Interestingly, although GFP and CGRP/substance $\mathrm{P}$ fibers were present in the same lamina, we did not observe any significant overlap at the single fiber level between TRPM ${ }^{E G F P f}$ afferents and CGRP or substance P fibers (Fig. $4 G-R$ ).

We also stained spinal cord sections of TRPM $8^{\text {EGFPf/EGFPf }}$ mice with markers for spinal cord neurons (in addition to afferent markers discussed above) that are present in distinct layers of the dorsal horn. We did not observe any coexpression with glutamic acid decarboxylase 67 (GAD67), which is expressed primarily in lamina III (Fig. $5 A-C$ ) (Mackie et al., 2003). We did see overlap with GAD65, which we found to be primarily expressed in lamina I of the dorsal horn (Fig. $5 D-I$ ) (Mackie et al., 2003). GAD65 synthesizes the inhibitory neurotransmitter $\mathrm{GABA}$, and $\mathrm{GAD} 5^{+}$neurons may form axoaxonic synapses on primary afferent terminals (Barber et al., 1978). The level of resolution observed here makes it difficult to ascertain whether TRPM $8^{E G F P f}$ afferents make synaptic contacts with GAD65 ${ }^{+}$neurons. We also observed overlap with neurokinin1 (NK1) or substance $\mathrm{P}$ receptor, which has been found to make up nearly $80 \%$ of the projection neurons in lamina I of the rat (Fig. 5J-O) (Todd et al., 2002) However, a high-resolution view of lamina I showed that the majority of TRPM $8^{E G F P f}$ afferents do not appear to make direct contacts with $\mathrm{NK}^{+}{ }^{+}$neurons (Todd et al., 2002). From these studies, it is clear that TRPM $8^{E G F P f}$ afferents project primarily to lamina I of the dorsal horn of the spinal cord, making this projection pattern distinct from other known spinal cord markers, and this projection pattern is in line with previous electrophysiological experiments, which found specific cool-sensing lamina I interneurons (see Discussion).

\section{TRPM8 ${ }^{E G F P f}$ free nerve endings project to multiple}

termination zones in the epidermis of the glabrous skin of the hindpaw

Virtually nothing is known about where the exact peripheral termination sites of cool fibers and/or TRPM8 neurons are located. This is an important matter, because the free nerve endings in the skin are the sites where, presumably, temperature information is

\section{M8-EGFPf Merge}
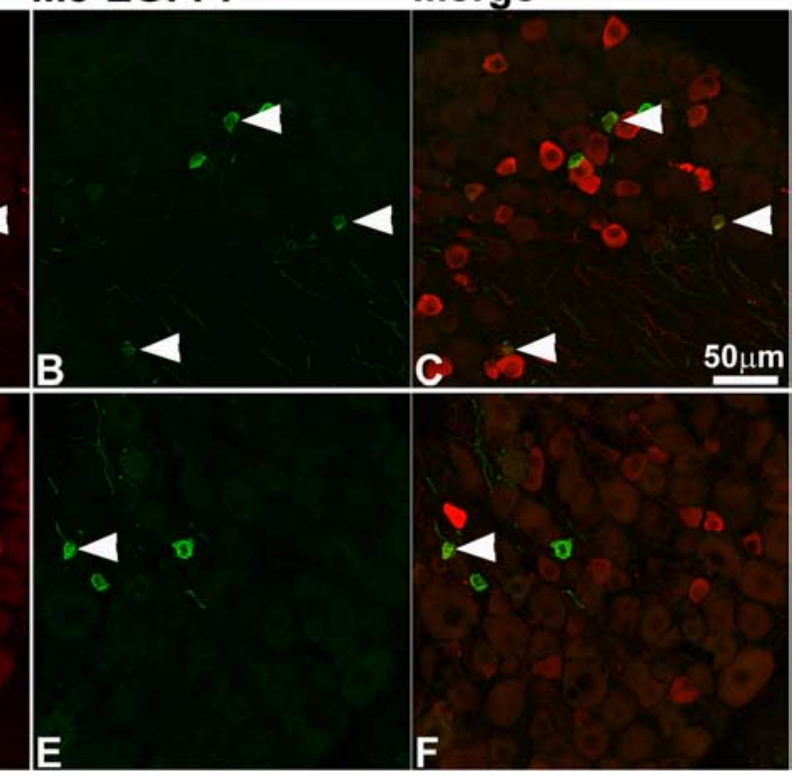

$\mathbf{F}$

Figure 3. TRPV1 expression is upregulated in TRPM8 $8^{\text {EGFPf }}$ neurons after CFA injection. DRG neurons from a TRPM8 ${ }^{\text {EGFPf/+ }}$ mouse injected with CFA $(\boldsymbol{A}-\boldsymbol{C})$ and uninjected TRPM $8^{\text {EGFPf/+ }}$ control $(\boldsymbol{D}-\boldsymbol{F})$ were stained with antibodies against TRPV1 (red). $T R P M 8^{E G F P f}$ neurons were visualized by endogenous EGFPf (green). Arrowheads indicate examples of double-labeled neurons. Scale bar (in $\mathbf{C}$ ) is the same for all panels.

converted into electrical activity. Recent investigations of CGRP and IB4 nerve endings have suggested an organization within the epidermis that is reminiscent of layers within the spinal cord (Zylka et al., 2005; Liu et al., 2007). We stained glabrous skin sections with anti-GFP to visualize TRPM $8^{E G F P f}$ free nerve endings and anti-CGRP, which marks peptidergic fibers known to innervate many structures, including the epidermis in glabrous skin. It was previously shown that Mrgprd $^{+}$nonpeptidergic IB4 ${ }^{+}$ free nerve endings constitute virtually all nonpeptidergic innervation of the epidermis and that together with CGRP-expressing neurons account for nearly all epidermal free nerve endings (Zylka et al., 2005). We observed TRPM ${ }^{E G F P f}$ free nerve endings terminate at the stratum spinosum, where the majority of $\mathrm{CGRP}^{+}$fibers terminate, as well as at the stratum granulosum, where all $\mathrm{Mrgprd}^{+}$fibers terminate (Zylka et al., 2005) (Fig. 6A$F$ ). TRPM $8^{E G F P f}$ free nerve endings were relatively rare with only a few positive epidermal nerve endings observed per section (reflecting the smaller population of neuronal cell bodies that TRPM8 is expressed in compared with CGRP or IB4). In addition, TRPM $8^{E G F P f}$ free nerve endings that terminated in the stratum granulosum exhibited the meandering profile described for Mrgprd $^{+}$fibers (Zylka et al., 2005). We did observe multiple TRPM8 ${ }^{E G F P f}$ fibers coursing through the dermis but did not observe any specific innervation of structures located in the dermis including hair follicles and blood vessels, which were positive for CGRP innervation (Fig. 6D-I) (data not shown), although it is difficult to determine where a sensory fiber is terminating without an obvious endpoint like the epidermis. Nor did we observe colocalization between TRPM ${ }^{E G F P f}$ fibers and CGRP, although TRPM ${ }^{E G F P f}$ fibers and CGRP ${ }^{+}$fibers were often intertwined up to and sometimes into the epidermis (Fig. 6). The location of $T R P M 8^{E G F P f}$ free nerve endings in the epidermis of glabrous skin puts these fibers in the optimal location to detect changes in ambient temperature. 


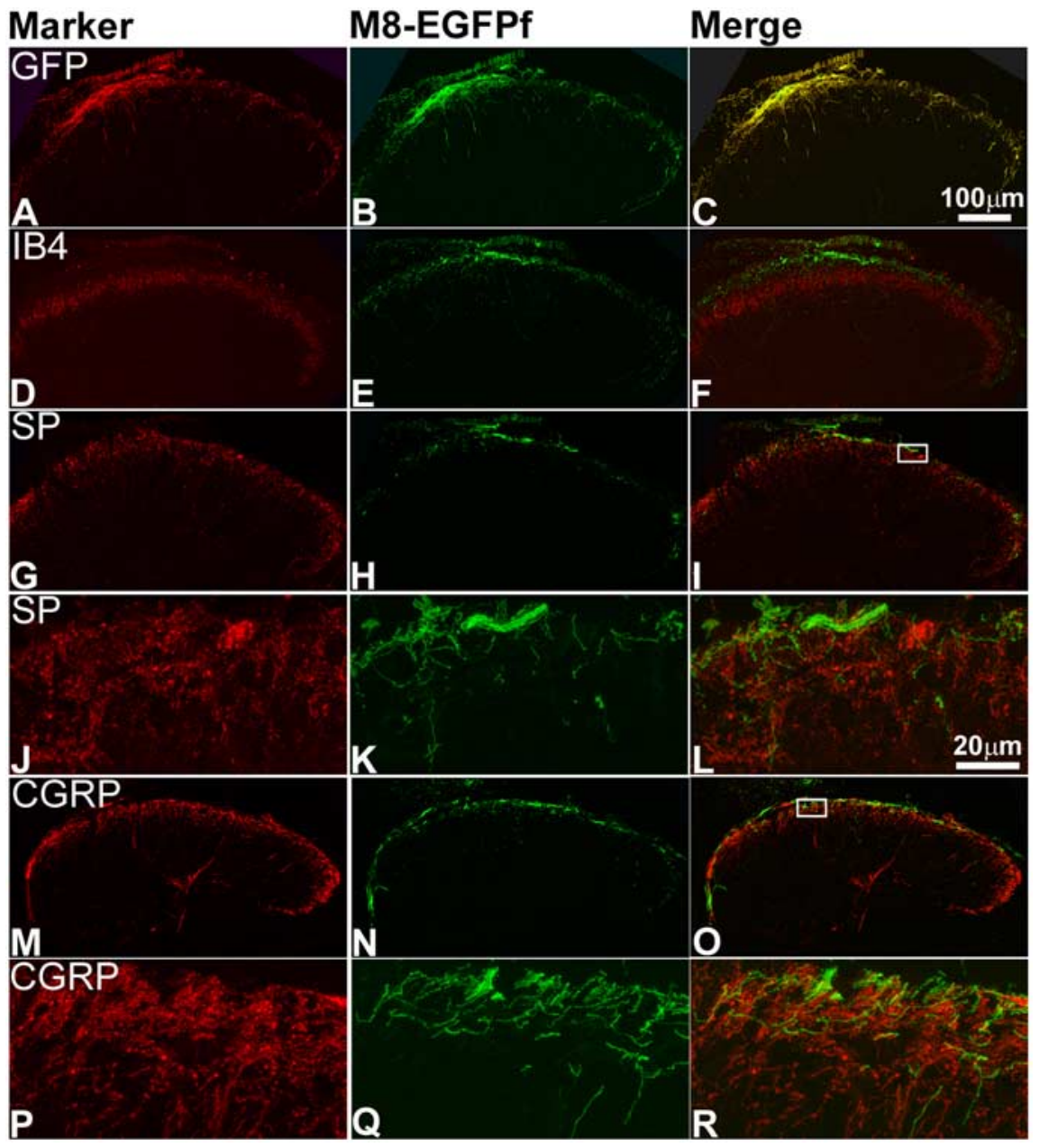

Figure 4. TRPM $8^{E G F P f}$ neurons terminate in lamina l of the spinal cord dorsal horn. $A-\boldsymbol{R}$, Confocal images of the lumbar region of adult spinal cord from TRPM8 ${ }^{\text {EGPF/EGFPf }}$ mice were stained with antibodies against GFP or sensory neuron markers (red). TRPM8 ${ }^{\text {EGPF }}$ neurons were visualized by endogenous EGFPf (green). The boxed regions in $I$ and 0 were reimaged at $60 \times$ with $2 \times$ digital zoom and shown in $\boldsymbol{J}-\boldsymbol{L}$ and $\boldsymbol{P}-\boldsymbol{R}$, respectively. SP, Substance $P$. Scale bar (in $\boldsymbol{C}$ ) is the same for $\boldsymbol{A}-\boldsymbol{I}, \boldsymbol{M}-\mathbf{0}$. Scale bar (in $\boldsymbol{L}$ ) is the same for $\boldsymbol{J}-\boldsymbol{L}, \boldsymbol{P}-\boldsymbol{R}$.

\section{$T R P M 8^{E G F P f}$ fibers label the bush/cluster free nerve endings} that terminate in the epidermis of the mystacial pad

There are no specific markers for most of neurons that innervate the epidermis of the intervibrissal fur of the mystacial pad. These neurons have been found to be both IB4 ${ }^{-}$and nonpeptidergic (Fundin et al., 1997). The free nerve endings of these neurons have been classified into four different subgroups: (1) bush endings, which are comprised of multiaxonal bundles of unmyelinated $\mathrm{C}$ - and $\mathrm{A} \delta$-fibers, including, in rare cases, $\mathrm{CGRP}^{+}$fibers that ascend into the epidermis and then branch into dense bush of terminals that can extend to the stratum lucidum; (2) cluster endings that arise from a single axon, which branch into loosely spaced cluster of terminals; (3) radiating free nerve endings, which have relatively few branches, but do show some immunoreactivity for CGRP; and (4) pencillate endings, which are comprised of single axons that branch into a simple horizontal ending (Fundin et al., 1997; Muller, 1999). To ascertain where TRPM $8^{E G F P}$ fibers terminate in the skin of the mystacial pad, we costained sections of the mystacial pad from TRPM $8^{E G F P f /+}$ mice with antibodies to GFP and CGRP (Fig. 7). Strikingly, we found examples of TRPM $8^{E G F P}$ fibers that represent all four subtypes of free nerve endings in the mystacial pad (Fig. 7). It was difficult to differentiate between bush and cluster termini because we ob- served both densely and loosely branched terminals that seemed to arise from only one axon; we therefore referred to these terminals as bush/cluster terminals (Fig. 7) (Muller, 1999). In addition, we did not observe any colocalization of CGRP with TRPM8 ${ }^{E G F P f}$-labeled bush/cluster endings (Fig. 7). We also observed TRPM ${ }^{\text {EGFPf }} \mathrm{fi}^{-}$ bers that appear to abut the outside of what we believe to be sebaceous glands, but we cannot say with certainty if these fibers are innervating this tissue or just traveling around it to reach the epidermis (Fig. 7). Differences in the sensory properties of these subtypes of free nerve endings is not known, but our studies suggest that at least some of the bush/cluster endings represent cool fibers.

\section{TRPM8 ${ }^{E G F P f}$ free nerve endings form bundles around taste buds but do not innervate taste buds}

The sensory innervation of the fungiform papillae on the dorsal tongue is derived from two cranial nerves: the lingual branch of the trigeminal nerve, which provides somatosensory innervation, and the chorda tympani branch of the facial nerve, which innervates the taste receptor cells (TRCs) of the taste bud. The peripheral endings of the lingual nerve terminate in the epithelium and connective tissue of the fungiform papillae and do not innervate TRCs (Montavon et al., 1996). We observed that TRPM8 ${ }^{E G F P f}$ fibers were rich in the fungiform papillae of the tongue, similar to findings previously reported (Fig. 8) (Abe et al., 2005). Interestingly, TRPM $8^{\text {EGFPf }}$ fibers seemed to terminate in same type of bush/ cluster endings that we observed in the mystacial pad. Bundles of TRPM $8^{\text {EFPf }}$ and CGRP fibers projected to the outer layer of the epithelium of the fungiform papillae but did not penetrate into the taste buds (Fig. $8 A-C$ ). We did observe many fungiform papillae that were richly innervated by TRPM $8^{E G F P f}$ fibers but showed little immunoreactivity for CGRP (Fig. $8 D-F)$. We also observed single TRPM ${ }^{E G F P f}$ and CGRP fibers that innervated the nongustatory epithelia (Fig. $8 G-I$ ). To confirm that TRPM ${ }^{E G F P f}$ fibers do not innervate taste bud cells, we costained fungiform papillae with anti-gustducin (a marker for TRCs) and observed no direct contact between TRPM $8^{\text {EGFPf }}$ fibers and gustducin-positive TRCs (Fig. $8 J-L$ ). These data indicate that TRPM8 innervation of the tongue arises from the trigeminal nerve and that TRPM $8^{E G F P f}$ fibers do not appear to innervate taste bud cells.

\section{Discussion}

There is unambiguous evidence that TRPM8 is a major sensor of environmental cold temperatures. Indeed, TRPM8 appears to be necessary and sufficient for cold sensitivity. Expressing TRPM8 induces cold sensitivity in a variety of cells that are cold insensitive (McKemy et al., 2002; Peier et al., 2002). Analyses of TRPM8deficient mice have shown that innocuous cold sensitivity assayed via physiological or behavioral assays are either eliminated 
or dramatically reduced (Bautista et al., 2007; Colburn et al., 2007; Dhaka et al., 2007). In this study, we show that virtually all TRPM8-expressing neurons (as assayed by EGFPf) in culture respond to cooling and menthol, reinforcing a direct role of these neurons in cold thermosensation. This data also functionally validates that EGFPf is accurately labeling TRPM8positive neurons. We further show that EGFPf-positive sensory neurons from TRPM8 ${ }^{\text {EGFPf/EGFPf }}$ homozygous mice are present (in vivo and in culture), but no longer respond robustly to a cooling stimulus in culture. Therefore, the TRPM8 expression is not required for the survival of these neurons, but is required for cold responses. The remaining few cold responses in DRGs from TRPM8 ${ }^{\text {EGFPf/EGFPf }}$ mice are interesting, and may suggest the existence of another receptor contributing to cold sensitivity of TRPM8-positive neurons.

Given the established involvement of TRPM8 in cold sensation, it befits a careful study of the cellular properties of the neurons that express the ion channel, because they represent one of the few instances in which a molecule clearly marks a functionally defined subpopulation of DRG neurons. As assayed by EGFPf expression in DRG cell bodies, skin projections, and spinal cord projections, we can conclude that TRPM8 mainly marks a unique population of DRG neurons that do not express any nociceptive markers. This is based on our findings that $>80 \%$ of TRPM $8^{E G F P f}$ neurons do not express TRPV1, CGRP, or IB4 (it is widely accepted that most if not all nociceptive neurons would express one of those three markers) (Woolf and $\mathrm{Ma}$, 2007). Indeed, Hensel and colleagues studied the physiological properties of innocuous cold fibers decades ago, and could identify nerve endings in the skin that responded to cooling alone, but not to any other innocuous or noxious stimuli (Hensel, 1981). The expression pattern of TRPM8 is also in accord with the primary phenotype of TRPM8-deficient mice in innocuous thermosensation.

The expression of EGFPf in the periphery and spinal cord also corroborates the conclusion that TRPM ${ }^{E G F P f}$ mainly marks a unique population distinct from nociceptive units. In the periphery, TRPM $8^{E G F P f}$ projections were observed extending past the dermis, into the outermost layers of the epidermis. Although TRPM ${ }^{E G F P f}$ fibers were in close apposition to CGRP, the individual TRPM8 ${ }^{E G F P f}$ fibers were distinct. Zylka et al. (2005) have previously shown that Mrgprd- and CGRP-positive fibers within the epidermis account for all but a minority of total projections there. Based on our results, we would conclude that TRPM8 must be labeling most of these remaining fibers, because EGFPf is not expressed with either CGRP or IB4 (which completely overlaps with Mrgprd). Therefore, cold-sensitive fibers represent another unique population of nerve endings in the layers of the epidermis.

Our studies also show that all four classes of epidermal IB4 ${ }^{-}$/ nonpeptidergic sensory free nerve endings of the intervibrissal same for $\mathbf{G}-\mathbf{I}, \mathbf{M}-\mathbf{0}$.

\section{M8-EGFPf Merge}
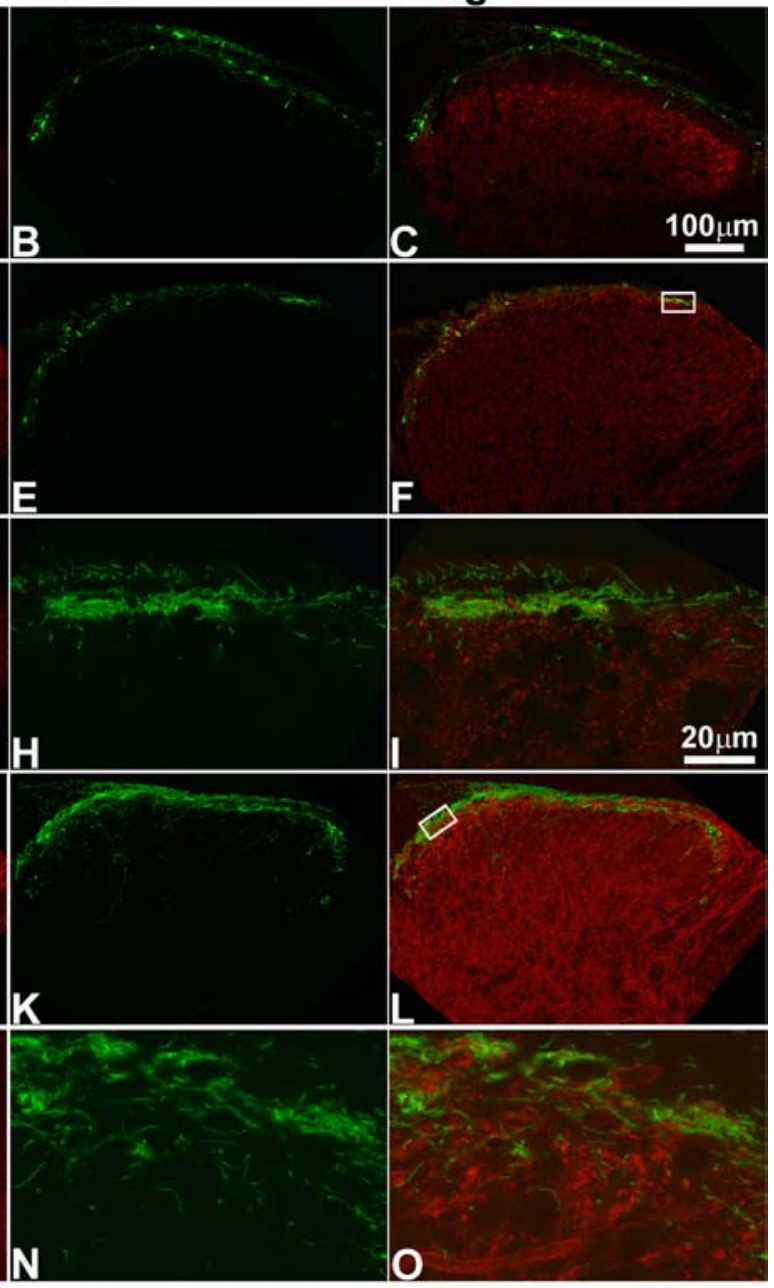

Figure 5. TRPM8 $8^{E G F P f}$ fibers colocalize with spinal cord neurons present in lamina I of the spinal cord dorsal horn. Confocal images of the lumbar region of adult spinal cord from TRPM8 ${ }^{E G F P f / E G F P f}$ mice. $\boldsymbol{A}-\mathbf{0}$, were stained with spinal cord neuron markers (red). TRPM $8^{\text {EGFP }}$ neurons were visualized by endogenous EGFPf (green). The boxed regions in $\boldsymbol{F}$ and $\boldsymbol{L}$ were reimaged at $60 X$ with $2 \times$ digital zoom and shown in $\mathbf{G}-\boldsymbol{I}$ and $\boldsymbol{M}-\boldsymbol{L}$, respectively. Scale bar (in $\boldsymbol{C}$ ) is the same for $\boldsymbol{A}-\boldsymbol{F}, \boldsymbol{J}-\boldsymbol{L}$. Scale bar (in $\boldsymbol{I}$ ) is the

fur of the mystacial pad, which up until now have had no specific markers, are labeled by TRPM ${ }^{E G F P f}$ afferents. Differences in the sensory properties of these classes of free nerve endings are not understood. The simple radiating and pencillate nerve endings may have the same properties as similar nerve endings found throughout the epidermis. The intriguingly shaped bush/cluster endings have been proposed to be C-mechanoreceptive or thermoreceptive "hotspots" by virtue of their contact with skin over a large surface area (Fundin et al., 1997; Muller, 1999). The presence of TRPM8 in all subtypes suggests that these endings play a role in the detection of cool temperature, and perhaps the sensitivity of these fibers to cool temperature is determined by their architecture.

We also found that TRPM $8^{\text {EFFP }}$ fibers richly innervated the epithelial tissue surrounding the taste buds of the fungiform papillae of the tongue but did not provide any innervation to the TRCs of the taste buds, similar to what was previously reported (Abe et al., 2005). These data indicate that although TRPM8 certainly has a role in how temperature is perceived on the tongue, it is probably not involved in mediating thermally induced shifts in taste at the level of the taste bud. 


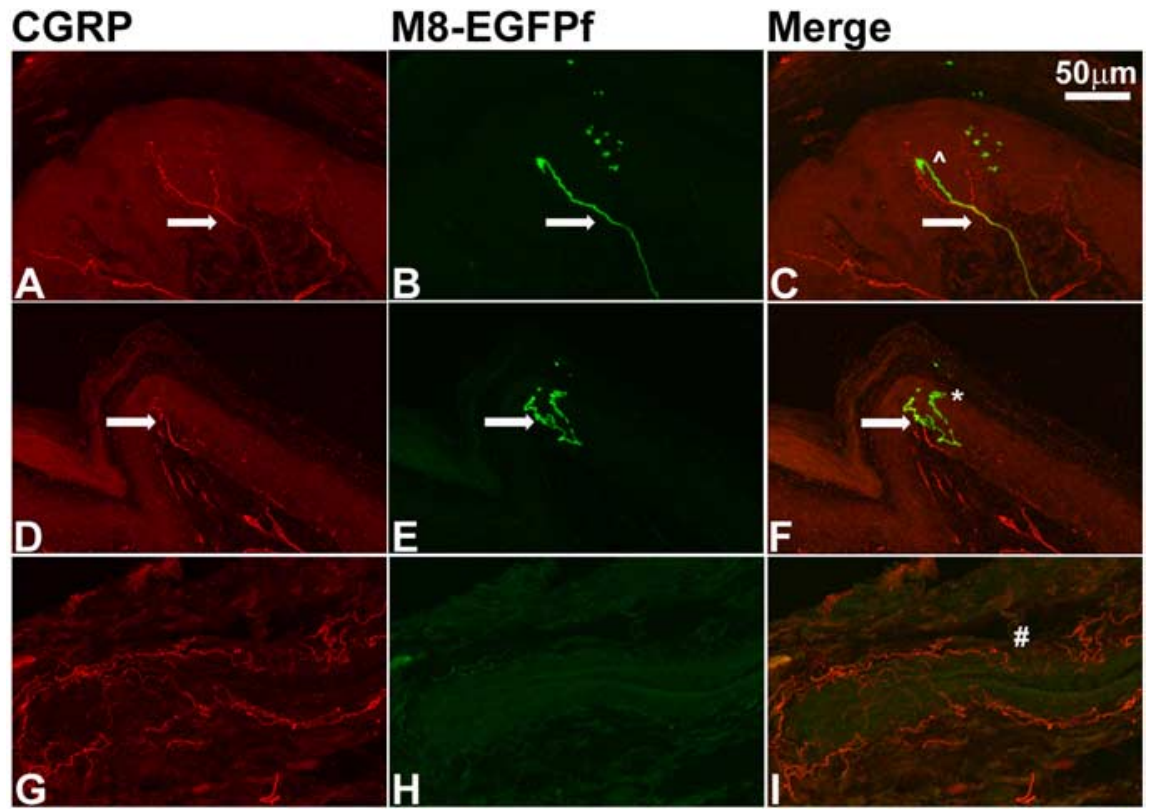

Figure 6. TRPM $8^{E G F P f}$ epidermal free nerve endings project to multiple termination zones in glabrous skin. $\boldsymbol{A}-\boldsymbol{F}$, Confocal images of CGRP (red) and TRPM8 $8^{\text {EGPF }}$ (green) epidermal free nerve endings in the glabrous skin from TRPM $8^{\text {EGFPf/EGPP }}$ mice. "marks the stratum spinosum; * marks the stratum granulosum; arrows mark intertwined fibers. G-I, Blood vessel is innervated with CGRP (red) fibers and has no innervation from TRPM $8^{\text {EGFP }}$ fibers. \# symbol marks blood vessel. Scale bar (in C) is the same for all panels.

\section{CGRP}

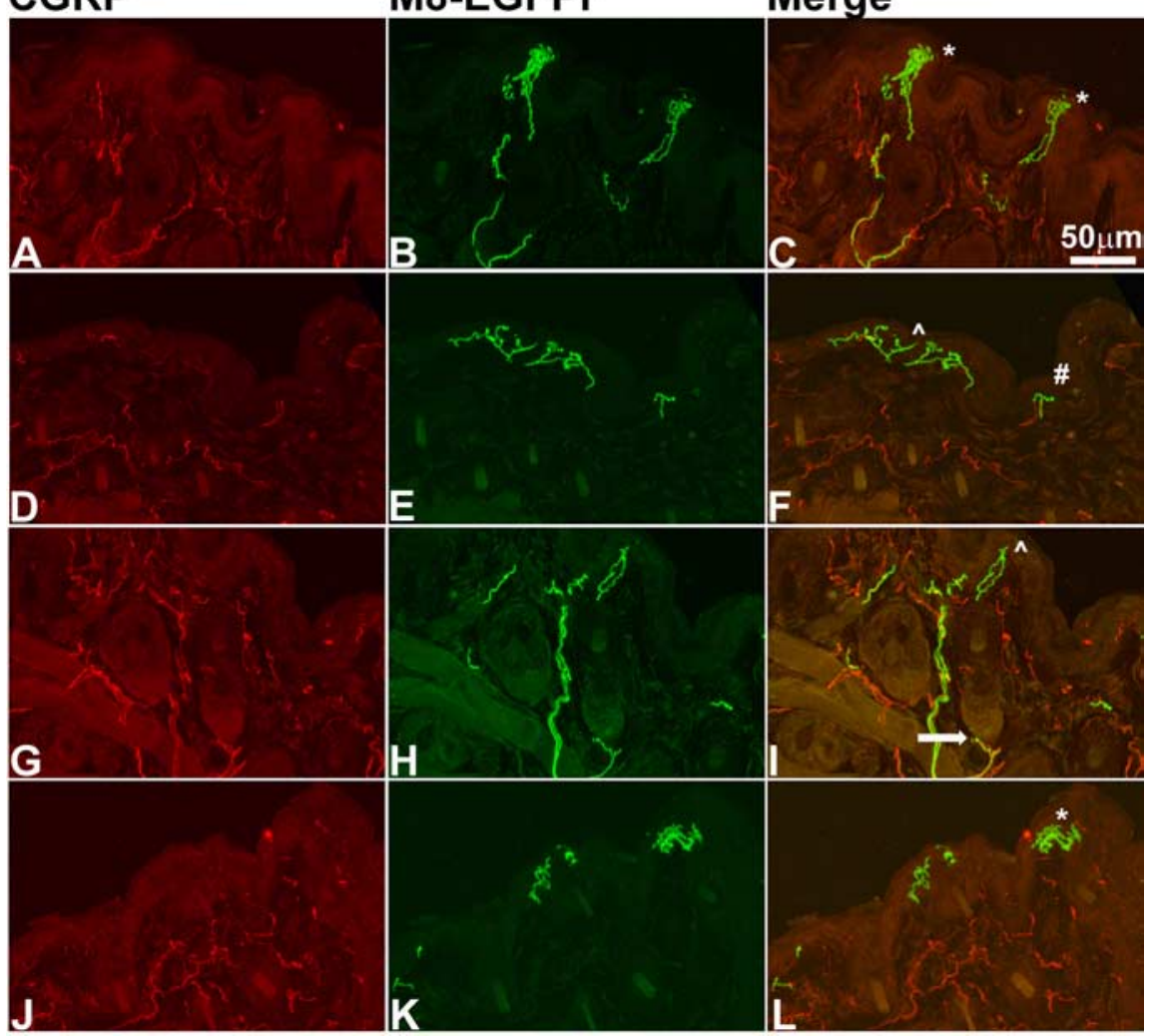

Figure 7. TRPM $8^{E G F P f}$ epidermal free nerve endings mark unique classes of sensory nerve endings in the mystacial pad. $\boldsymbol{A}-\boldsymbol{L}$, Confocal images of CGRP (red) and TRPME ${ }^{\text {GGPF }}$ (green) epidermal free nerve endings in the mystacial pad from TRPM $8^{\text {EGPF/ } /}$ mice. " marks example of radiating free nerve endings; ${ }^{*}$ marks examples of bush/cluster free nerve endings; \# marks example of pencillate/horizontal free nerve endings, and arrow marks example of $T R P M 8^{E G F P f}$ fibers near sebaceous glands. Scale bar (in C) is the same for all panels.
At the central end, TRPM ${ }^{E G F P f}$ afferents send projections to layer I of the spinal cord. Although $\mathrm{CGRP}^{+}$and TRPM8 $8^{\text {EGFPf }}$ neurons projected to the same region in layer I (CGRP labels layers $\mathrm{I}_{\text {and }} \mathrm{II}_{\mathrm{o}}$ outside), the costaining clearly showed segregation of individual endings. Interestingly, electrophysiological recordings have highlighted the existence of distinct thermoreceptive (COOL), nociceptive (NS), and polymodal nociceptive (HPC) layer I interneurons (Christensen and Perl, 1970; Craig and Dostrovsky, 2001). Our results suggest that the majority of TRPM8positive fibers innervate the previously defined COOL layer I spinal cord neurons.

A small percentage of EGFPf-positive neurons do express TRPV1 (12\% of GFPpositive, $1 \%$ of total DRG neurons). This relatively minor population could have an important impact, because an additional role for TRPM8 in cold nociception and cold allodynia has been suggested. Interestingly, CFA (an inflammatory agent) administration to the paw of mice did not increase the number of presumptive TRPM8-positive neurons, but as expected, it increased TRPV1 expression (Amaya et al., 2003; Obata et al., 2005). Consequently, EGFPf-TRPV1 coexpression increased from 12 to $20 \%$ of total GFP. Perhaps, the up to $50 \%$ co-response to menthol and capsaicin observed in this and other studies of DRG cultures represents a similar inflammatory or injury state of axotomized cultures that brings about higher levels of TRPM8-TRPV1 coexpression compared with in vivo (McKemy et al., 2002; Peier et al., 2002; Story et al., 2003; Babes et al., 2004). Alternatively, TRPM8 and TRPV1 coexpression in vivo might be underestimated when using in situ hybridization, antibody staining, or EGFPf expression. Together, it is intriguing to suggest that TRPM8 is present in two labeled lines: a majority labeling innocuous cold-sensing neurons (not coexpressing TRPV1); and a minority, noxious cold-sensing neurons (coexpressing TRPV1) (Chung and Caterina, 2007). However, it is also possible that the small numbers of TRP8-TRPV1coexpressing neurons are not abundant enough to have a major physiological impact.

Our study uses genetics to mark TRPM8-positive neurons and their projections. The cumulative data suggest that TRPM8 expression parallels the anatomical and functional properties of coldsensitive fibers and their projections as assayed by in vivo electrophysiological recordings. Thus, we would predict that TRPM8 marks these well studied but elu- 
sive cool neurons. The TRPM $8^{E G F P f}$ mice will be further useful in mapping the exact peripheral and synaptic connections of these neurons, and to evaluate the detailed functional properties of these neurons in normal and injury states.

\section{References}

Abe J, Hosokawa H, Okazawa M, Kandachi M, Sawada Y, Yamanaka K, Matsumura K, Kobayashi S (2005) TRPM8 protein localization in trigeminal ganglion and taste papillae. Brain Res Mol Brain Res 136:91-98.

Amaya F, Oh-hashi K, Naruse Y, Iijima N, Ueda M, Shimosato G, Tominaga M, Tanaka Y, Tanaka M (2003) Local inflammation increases vanilloid receptor 1 expression within distinct subgroups of DRG neurons. Brain Res 963:190-196.

Babes A, Zorzon D, Reid G (2004) Two populations of cold-sensitive neurons in rat dorsal root ganglia and their modulation by nerve growth factor. Eur J Neurosci 20:2276-2282.

Barber RP, Vaughn JE, Saito K, McLaughlin BJ, Roberts E (1978) GABAergic terminals are presynaptic to primary afferent terminals in the substantia gelatinosa of the rat spinal cord. Brain Res 141:35-55.

Bautista DM, Siemens J, Glazer JM, Tsuruda PR, Basbaum AI, Stucky CL, Jordt SE, Julius D (2007) The menthol receptor TRPM8 is the principal detector of environmental cold. $\mathrm{Na}$ ture 448:204-208.

Christensen BN, Perl ER (1970) Spinal neurons specifically excited by noxious or thermal stimuli: marginal zone of the dorsal horn. J Neurophysiol 33:293-307.

Chung MK, Caterina MJ (2007) TRP channel knockout mice lose their cool. Neuron 54:345-347.

Colburn RW, Lubin ML, Stone Jr DJ, Wang Y, Lawrence D, D'Andrea MR, Brandt MR, Liu Y, Flores CM, Qin N (2007) Attenuated cold sensitivity in TRPM8 null mice. Neuron 54:379-386.

Craig AD, Dostrovsky JO (2001) Differential projections of thermoreceptive and nociceptive lamina I trigeminothalamic and spinothalamic neurons in the cat. J Neurophysiol 86:856-870.

Dhaka A, Viswanath V, Patapoutian A (2006) TRP ion channels and temperature sensation. Annu Rev Neurosci 29:135-161.

Dhaka A, Murray AN, Mathur J, Earley TJ, Petrus MJ, Patapoutian A (2007) TRPM8 is required for cold sensation in mice. Neuron 54:371-378.

Fundin BT, Arvidsson J, Aldskogius H, Johansson O, Rice SN, Rice FL (1997) Comprehensive immunofluorescence and lectin binding analysis of intervibrissal fur innervation in the mystacial pad of the rat. J Comp Neurol 385:185-206.

Han ZS, Zhang ET, Craig AD (1998) Nociceptive and thermoreceptive lamina I neurons are anatomically distinct. Nat Neurosci 1:218-225.

Hensel H (1981) Thermoreception and temperature regulation. Monogr Physiol Soc 38:1-321.

Hensel H, Zotterman Y (1951) The response of the cold receptors to constant cooling. Acta Physiol Scand 22:96-105.

Hensel H, Andres KH, von During M (1974) Structure and function of cold receptors. Pflugers Arch 352:1-10.

Julius D, Basbaum AI (2001) Molecular mechanisms of nociception. Nature 413:203-210.

Koltzenburg M, Stucky CL, Lewin GR (1997) Receptive properties of mouse sensory neurons innervating hairy skin. J Neurophysiol 78:1841-1850.

Lewin GR, Moshourab R (2004) Mechanosensation and pain. J Neurobiol 61:30-44.

Light AR, Trevino DL, Perl ER (1979) Morphological features of functionally defined neurons in the marginal zone and substantia gelatinosa of the spinal dorsal horn. J Comp Neurol 186:151-171.

Liu Q, Vrontou S, Rice FL, Zylka MJ, Dong X, Anderson DJ (2007) Molec-
M8-EGFPf

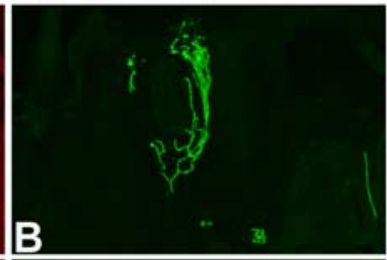

Merge
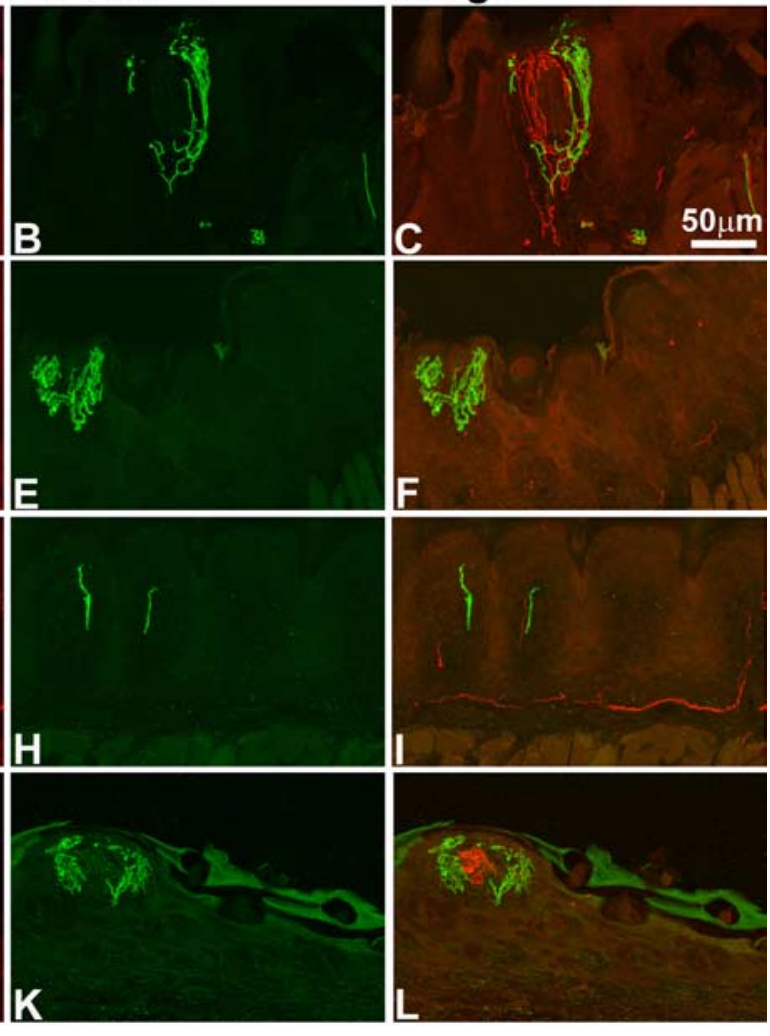

든

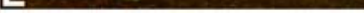

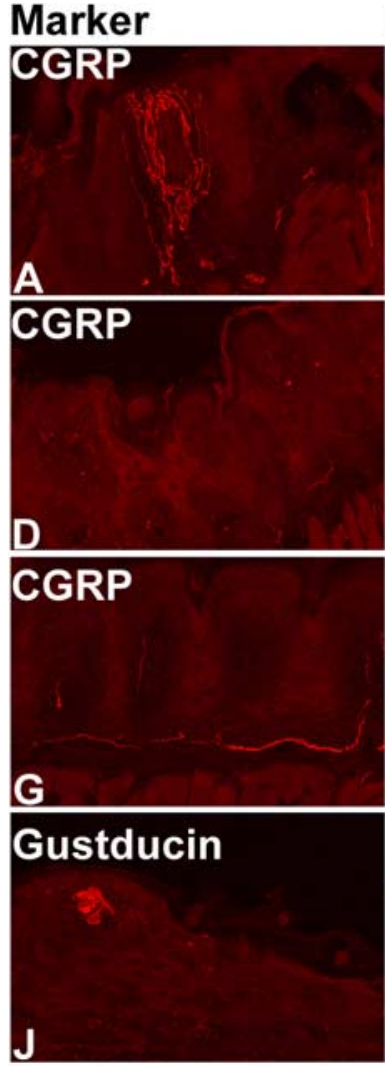

Figure 8. TRPM8 $8^{E G F P}$ epidermal free nerve endings innervate tissue around but not into taste buds of the tongue. $A-I$ Tes of CGRP (red) and TRPM $8^{\text {EGFP }}$ (green) epidermal free nerve endings in fungiform papillae $(\boldsymbol{A}-\boldsymbol{F})$ and epidermal tissue $(\mathbf{G}-\mathbf{I})$ of the tongue. J-L, Confocal images of gustducin (red)-positive taste buds and TRPM8 ${ }^{E G F P F}$ (green) epidermal free nerve endings in fungiform papillae. Scale bar (in $\boldsymbol{C}$ ) is the same for all panels.

ular genetic visualization of a rare subset of unmyelinated sensory neurons that may detect gentle touch. Nat Neurosci 10:946-948.

Lumpkin EA, Caterina MJ (2007) Mechanisms of sensory transduction in the skin. Nature 445:858-865.

Mackie M, Hughes DI, Maxwell DJ, Tillakaratne NJ, Todd AJ (2003) Distribution and colocalisation of glutamate decarboxylase isoforms in the rat spinal cord. Neuroscience 119:461-472.

McKemy DD, Neuhausser WM, Julius D (2002) Identification of a cold receptor reveals a general role for TRP channels in thermosensation. Nature 416:52-58.

McNeill DL, Coggeshall RE, Carlton SM (1988) A light and electron microscopic study of calcitonin gene-related peptide in the spinal cord of the rat. Exp Neurol 99:699-708.

Montavon P, Hellekant G, Farbman A (1996) Immunohistochemical, electrophysiological, and electron microscopical study of rat fungiform taste buds after regeneration of chorda tympani through the non-gustatory lingual nerve. J Comp Neurol 367:491-502.

Muller T (1999) Characteristic intraepidermal nerve fibre endings of the intervibrissal fur in the mystacial pad of the rat: morphological details revealed by intravital methylene blue staining and the zinc iodideosmium tetroxide technique. J Anat 195:147-152.

Nealen ML, Gold MS, Thut PD, Caterina MJ (2003) TRPM8 mRNA is expressed in a subset of cold-responsive trigeminal neurons from rat. J Neurophysiol 12:12.

Obata K, Katsura H, Mizushima T, Yamanaka H, Kobayashi K, Dai Y, Fukuoka T, Tokunaga A, Tominaga M, Noguchi K (2005) TRPAl induced in sensory neurons contributes to cold hyperalgesia after inflammation and nerve injury. J Clin Invest 115:2393-2401.

Okazawa M, Inoue W, Hori A, Hosokawa H, Matsumura K, Kobayashi S (2004) Noxious heat receptors present in cold-sensory cells in rats. Neurosci Lett 359:33-36.

Patapoutian A, Peier AP, Story GM, Viswanath V (2003) ThermoTRPs and beyond: mechanisms of temperature sensation. Nat Rev Neurosci 4:529-539. 
Peier AM, Moqrich A, Hergarden AC, Reeve AJ, Andersson DA, Story GM, Earley TJ, Dragoni I, McIntyre P, Bevan S, Patapoutian A (2002) A TRP channel that senses cold stimuli and menthol. Cell 108:705-715.

Proudfoot CJ, Garry EM, Cottrell DF, Rosie R, Anderson H, Robertson DC, Fleetwood-Walker SM, Mitchell R (2006) Analgesia mediated by the TRPM8 cold receptor in chronic neuropathic pain. Curr Biol 16:1591-1605.

Reid G, Babes A, Pluteanu F (2002) A cold- and menthol-activated current in rat dorsal root ganglion neurones: properties and role in cold transduction. J Physiol (Lond) 545:595-614.

Silverman JD, Kruger L (1990) Selective neuronal glycoconjugate expression in sensory and autonomic ganglia: relation of lectin reactivity to peptide and enzyme markers. J Neurocytol 19:789-801.

Snider WD, McMahon SB (1998) Tackling pain at the source: new ideas about nociceptors. Neuron 20:629-632.

Story GM, Peier AM, Reeve AJ, Eid SR, Mosbacher J, Hricik TR, Earley TJ,
Hergarden AC, Andersson DA, Hwang SW, McIntyre P, Jegla T, Bevan S, Patapoutian A (2003) ANKTM1, a TRP-like channel expressed in nociceptive neurons, is activated by cold temperatures. Cell 112:819-829.

Todd AJ (2002) Anatomy of primary afferents and projection neurones in the rat spinal dorsal horn with particular emphasis on substance $P$ and the neurokinin 1 receptor. Exp Physiol 87:245-249.

Todd AJ, Puskar Z, Spike RC, Hughes C, Watt C, Forrest L (2002) Projection neurons in lamina I of rat spinal cord with the neurokinin 1 receptor are selectively innervated by substance p-containing afferents and respond to noxious stimulation. J Neurosci 22:4103-4113.

Woolf CJ, Ma Q (2007) Nociceptors-noxious stimulus detectors. Neuron 55:353-364.

Zylka MJ, Rice FL, Anderson DJ (2005) Topographically distinct epidermal nociceptive circuits revealed by axonal tracers targeted to Mrgprd. Neuron 45:17-25. 